\title{
Introduction
}

\section{Translation as creation: the postcolonial influence}

\author{
Aline Remael \& Ilse Logie \\ Hoger Instituut voor Vertalers en Tolken, Hogeschool Antwerpen
}

Translation has meant different things at different times; it has always been an unstable concept. This instability has, for the most part, been due to variable views first on the relations between translated texts and their source and target languages, and later on similar binary relations between translated texts and their source and target cultures. The evolution of discussions in terms of faithful versus free translation, source text oriented versus target text oriented translation, and foreignizing versus domesticating translation with their varying focuses on either the source or the target end, reflects how approaches to translation often remain overdetermined by binary concepts (see Bandia, below) but also how new insights gradually enter the discussion. One such insight is that both translation and views on what translation should be, are determined by historical and ideologically coloured social practices. Indeed, as Theo Hermans writes "Cultures, communities and groups construe their sense of self in relation to others and by regulating the channels of contact with the outside world." (1999: 95) Translation is one such channel. Historical, audiovisual and postcolonial studies into the relations between translation and power have all demonstrated the influence of power and ideology on the production of translations and suggested new terms such as the 'metonymy' of translation (Tymoczko 1999) and 'transadaptation' rather than 'translation' for audiovisual texts (Gambier 2003) to deal with the complexity of relations that demonstrably transcends binary oppositions. The production of 'difference' in ever-changing gradations is - in some contexts - just as central a concern to translators as the production of 'equivalence' (taken in its hypothetical literal meaning). Which way the cat eventually jumps is determined by cultural-ideological norms just as much as functional ones. In fact, "[...] the normative apparatus which governs the selection, production and reception of translation, together with the way translation is conceptualized at certain moments, provides us with an index of cultural self-definition." (Hermans 1999: 95)

'Cultural self-definition' is, however, becoming increasingly problematic in a world torn between globalizing and localizing tendencies. On the one hand, the cultural identities of some minorities, for instance, are under threat in an anglicized MacWorld (see Snell-Hornby below), on the other hand, globalization stimulates extreme forms of localization or identity assertion, as the popularity of nationalist and religious forms of self-identification demonstrates. In between there lies a virtually limitless spectrum of interactional struggles and variable relations between more or less powerful actants, both locally and internationally. 
Indeed, the phenomena of economico-political globalization, diaspora and also colonial emancipation have contributed to the development of globalized cultures that erode concepts of culture and identity based on binary oppositions between first and third world, north and south, centre and periphery, but also source and target text. Increasingly, hybrid cultures are flourishing in the traditional centre, in the traditional peripheries and in the exchanges between them. Does this mean the time has come to refer the term 'equivalence' to the confines of history once and for all (see Bandia), and to replace it with the concept of 'translation as creation', as our title proposes? Some of the contributions suggest that even this title has been overtaken by events and that the term 'postcolonial', which still figures in it, does not cover today's complex and hybrid world that is the result of colonial and post-colonial as well as other global developments (e.g. Sales Salvador).

The study of translation has not only been crossing conceptual, but also disciplinary borders. Increased awareness of the cultural embeddedness of translation has been drawing the fields of translation studies and cultural studies closer together for some time now. In "The Translation Turn in Cultural Studies" Bassnett (1998) argues that it is time for cultural studies and translation studies to collaborate. On what seems to be a completely different plane, the original indebtedness of translation studies to linguistics may also be in the process of being reassessed. As Van Vaerenbergh (2002) writes in the introductory chapter to the first issue of Linguistica Antverpiensia New Series: translation studies is now also influencing linguistics, e.g. in the areas of text linguistics, pragmatics, cognitive approaches and developments resulting from technological innovations such as corpus research and localization. Language is culture. These developments too are due to the growing awareness of the interconnectedness of seemingly diverse forms of cultural production, of the multiple manners in which texts or cultural products are 'rewritten' and circulated (Calabrese Steimberg), and the different ways in which they are read or watched, that is, received. According to some, translation has actually become a way of life in a world in which multilingualism and multiculturalism are the norm (see Sales Salvador; Martín Ruano) and Gentzler has pointed out that in some cases the position of translation scholars has become increasingly "Joycean": Lambert and Robyns, for example, (qtd. in Gentzler 2001: 192) claim that not only every text, but even every word contains 'translated' elements; they define translation as the result of a semiotic process, but also as a starting point for the study of the semiotic processes involved in the formation of discursive practices. Translation as a form of continuous semiosis between producers and receivers?

The call for papers for this collection started from very concrete questions about the concept and production of translation today, considered from a postcolonial perspective. The articles we have received supply answers from a variety of angles and ask further questions. Yet there is a considerable amount of uniformity or agreement in spite of, or within the difference. Two main sections have been distinguished. 
The first series of texts, grouped under the title WRITING AS TRANSLATION OR TRANSLATION AS WRITING: TRANSCULTURATION, topicalizes the contribution of translation to contemporary creative writing. The articles examine some of the varying relations between writing and translating, look into the reasons why the two activities have become increasingly indistinguishable and draw attention to the central place translation occupies in the poetics of postcolonial literature or, maybe we should say, 'world literature' today. The authors in the second section TRANSLATION STRATEGY, TRANSLATION POLICY, TRANSLATION THEORY appear to consider the concept of translation from a somewhat more traditional angle, but they too test the possibilities and limitations of translation as intercultural communication, which, again leads to questions concerning new conceptual approaches. In short, there is a considerable degree of interaction between the articles of both sections.

In Translation, ideology, and creativity Maria Tymoczko links $20^{\text {th }}$ century and current Irish literary production and creativity to the translations from previous centuries. These translations both supported and produced shifts in the representation, influence and shape of the Irish culture and language, leading to a valorization of Hiberno-English and the foundation of a new form of cultural literacy. The author starts from the Polysystem view that translation serves innovative purposes in literary systems that are in crisis, weak or relatively young, but moves from Polysystem theory to a concept of translation inspired by discourse theory. Translation is always a form of linguistic interface and therefore introduces discourse shifts, destabilizes received meanings, creates alternative views of reality, establishes new representations, and makes possible new identities, which may eventually lead to far-reaching creative results in a literary system and culture. These creative dimensions of translation are particularly apparent in postcolonial contexts, as the author demonstrates by analysing the nexus of language interface, translation, and literary creativity in Ireland from the end of the $19^{\text {th }}$ century to the present. Indeed, the connections between language interface, ideology, translation and literary creativity resurface in varying shapes in all subsequent articles.

Dora Sales Salvadores's 'I translate, therefore I am': la ficción transcultural entendida como literatura traducida en el polisistema poscolonial deals with two concrete examples of 'transcultural fiction' that may belong to an earlier stage in literary evolution than that considered by Tymoczko. Sales Salvador defines the concept of 'transculturation', which she prefers to 'postcolonialism', as the process of mutual influence and continuous transformation that cultures in contact undergo, often within the context of painful and unequal power relations. As translation becomes a way of life in multicultural societies, it also becomes a conscious and integral part of hybrid postcolonial texts or transcultural fiction. The work of the Peruvian writer José María Arguedas and that of the Indian writer Vikram Chandra are a case in point. Arguedas's writings embody the tragic coexistence of the world and languages of the Andes and the Spanish-language world of Peru. 
Vikram Chandra's mother tongue is Hindi, but he writes in English, India's second official language. For both authors translation has become a form of rewriting, a way to foreground certain aspects of their postcolonial identities by pushing the borders of what can be said in the languages of the 'centre'. The writings of both bilingual authors are examples of the metonymy of translation (Tymoczko 1999) as they translate themselves and certain aspects of their culture-bound world views into the other tongue, but present these translations as creative work. The distinction between intercultural writing and translation is a matter of degree, not of essence. What is more, the poetics of intercultural writers such as Arguedras and Chandra could provide translation strategies for those who, in turn, set out to translate this intercultural or translated literature: Sales Salvador therefore recommends such fiction as a source of inspiration and an object of study for translators wishing to respect their source authors' concerns, in spite of the globalizing tendencies of established cultural institutions.

Within the French Caribbean context, Catriona Cunningham explores yet another variant of text production which tests the borders between translation and creation on the levels of language, including oral language, and writing. And here too the borders of 'traditional' interlingual, even intercultural definitions of translation are superseded. In Beyond translation into chaos: exploring language movement in the French Caribbean, the author starts from the complex relations between French and Creole, as well as their roots in the region's history and in written versus oral traditions, to examine Chamoiseau's evolution in his creative uses of them. In his earlier work, a marqueur de paroles who acts as a pivot between the two worlds the languages represent, allows Chamoiseau to let his own intricate sociolinguistic reality enter the text. Metatextual comments are offered, while the orality of Creole is inserted into the written French through juxtaposition, giving the languages a parity of status they lack "in the real world". Like Glissant, Chamoiseau creates a 'bilangue' with shifting language layers, and a continuous process of translation appears to be materializing on the page. However, the term 'translation' may not be adequate for this continuous movement between languages: where does one language end and the other start? In fact, a new form of expression, a langage, is constructed in the space where speaking and writing meet. Still, fissures in communication are inevitable, but rather than resolving difference, Chamoiseau opts for a form of opacity that allows differences to exist side by side. A form of chaos that does justice to all is welcomed. Indeed, in Chamoiseau's later works there is a broadening of themes: while his characters come to terms with the idea that they are two in one, it is the evils of globalization that are further explored.

Echoes of the creation of a hybrid cultural form reverberate throughout Dominique Ranaivoson's contribution titled Les textes francophones malgaches sont-ils hybrides? Francophone Madagascan literature may have originated within a colonial context, it has meanwhile developed its very own voice in the francophone world, and its accessibility to a Frenchreading public may therefore be deceptive. Its language is still a variant of 
French, but it is in fact an 'interlangue' ( or a 'bilangue'?) and the literature's frame of reference is not only French, but also Madagascan culture: indigenous fabels, legends and oral narratives, evolving cultural traditions, historical particularities, but also specific literary and theatrical traditions. In short, the postcolonial writer is always a cultural translator, a 'transculturator' as Sales Salvador writes, and in a similar vein Ranaivoson also wonders whether and to what extent such works can or should be 'explained' to readers beyond Madagascar while safeguarding their specificity - a problem that is also addressed by Bandia and dealt with in more detail in the second half of this collection.

The uneasy and as yet unresolved cohabitation of different language traditions is thematized in La traduction dans L'amour, la fantasia d'Assia Djebar: une tunique de Nessus. In her study of the Algerian writer's novel, Katrien Lievois uncovers a mixture of biography and historiography that appears to be a hallmark of much postcolonial writing involving a search for cultural identity and meaning through different language interfaces. Here too the narrative develops against a multicultural and multilingual background, a tangle of oral and written sources that cannot be undone, involving not only French and Arabic, but also English, Spanish, Turkish and German. However, Djebar's novel offers a different perspective on language interface, it may be more pessimistic than those we have so far encountered, even if it is equally aware of the crucial role translation must play in intercultural communication. For Djebar, adopting French is not only an act of emancipation but also an act of betrayal, and the confrontation of the different languages with different power relations attached to them, remains a stuggle. The language interface is one of conflict in that the transition between languages requires different traditions of thought and the problems involved suggest deeply rooted power relations. L'amour, la fantasia plays with these irresolvable contradictions in different ways in different parts of the novel, however, and rather than evolving towards resolution, the relations between languages become increasingly laborious. Djebar seems caught in a double bind: an Algerian writer choosing French as a form of expression, she uses translation to give shape to her identity, and instances of communication that rely on a constant process of translation pervade the novel, yet the work also points to the ultimate failure of such communication.

The North African perspective examined in Abdelouahed Mabrour's La 'bi-langue' ou l'(en)jeu de l'écriture bilingue chez Abdelkebir Khatibi moves beyond this point. The article focuses on the Moroccan philosopher, poet and writer of essays, and especially on his autobiographical book Amour bilingue. Tensions between French and Arabic are its central theme. Is French a foreign language in Morocco, a second language or a language of privilege? What are its sociological and stylistic particularities and what connotations does it evoke? How do these tensions compare with the tensions between literary Arabic and the Moroccan variant that is only spoken? Here too echoes of Arabic regularly surface in the French text, for instance, when sociocultural or religious traditions are referred to, when the 
protagonist inadvertently starts reading from right to left, when he ponders the different gender of words in French and Arabic, when phonetic associations lead from one language to the other, ... French undergoes a transformation in this language mixture, in this 'bilangue' also encountered in Glissant and Chamoiseau (see Cunningham). Whereas in Djebar transitions between languages are hampered by different patterns of thought, in Khatibi, French is transformed into a more malleable instrument that can also express aspects of Arabic culture and therefore represents a different way of thinking. After or through conflict a new form of creation follows (see also Tymoczko).

Continuing along the line of defining the postcolonial condition as fundamentally transcultural, Maria E. Brunner's contribution Literarische Mehrsprachigkeit und Transkulturalität. Der Dialog zwischen den Kulturen und das Echo von Mimikry und sprachlicher Hybridität im Werk deutsch-türkischer Autorinnen concentrates on German-Turkish literature, more specifically on two recent publications by Dilek Zapctioglu (Der Mond isst die Sterne auf) and Emine S. Özdamar (Die Brücke vom goldenen Horn). The situation under scrutiny here is quite different sociogeographically, since it involves the study of new hybrid literary forms created by members of the Turkish (immigrant) community in Germany, one that was never really 'colonized' by the Germans. The article therefore demonstrates all the more forcibly how new cultural interfaces involving persistent language contact and unstable power relations stimulate cultural change and creativity through some translation variant, in very different contexts and beyond the strict 'postcolonial' sphere. In the novels under discussion, linguistic hybridity is combined with forms of mimicry to create ambivalent views on reality, while techniques of Verfremdung reminiscent of the theatre go hand in hand with linguistic experimentation and the creation of unexpected neologisms. Today, this type of literature is becoming increasingly popular in Germany, where it contributes to the erosion of outdated concepts of 'national' literature and to the recreation of western culture as a transcultural space.

Language contacts and cultural contacts across formerly unbridgeable divides, together with the former 'periphery's' emancipation indeed appear to be producing a (literary) world characterized by a diversity in which translation has become the standard form of communication and in which the creation of new forms is but the corollary of that. Has translation always been creation? Will the new views on writing as translation have an influence on translation 'proper', will they eradicate the boundaries between the concepts, will or have they affected translation theory? Paul Bandia's Postcolonialism and translation: the dialectic between theory and practice, discusses the interaction between translation theory and practice in the light of contributions from postcolonial studies, confirming many of the findings in the articles above, while providing a transition to the second set of texts. The author revisits the concept of writing as translation, investigating the varying scope of the culturally specific translational communication 
strategies that are consciously or unconsciously used in African Europeanlanguage works. In other words, he examines issues that also concern interlingual translators: the degree to which the writer-translator chooses to respect the translational norms of the receiving European culture or to prioritize formal and ideological representations of the (once) colonized source culture. He points to two trends that the African texts obviously share with those discussed by Sales, Cunningham, Ranaivoson, Lievois, Brunner ... that is, the far-reaching (in this case) African-based intertextuality that often inhabits them, but also the way in which they aim to create a 'textual middle', a multi-layering of different linguistic and cultural discourses. Looking at some concrete examples of strategies at work in the writing-astranslating process, Bandia paves the way for the analysis that will be required for the further translation of such writing (see also Sales Salvador and Ranaivoson) and concludes that these hybrid forms of discourse enhance our understanding of the role of translation as representation grounded in ideology (see also Tymoczko). Translation as a metaphor for postcolonial writing therefore broadens the horizon of the study of translation theory and practice, undermining the concepts of stable source and target texts and questioning the relentless search for equivalence. And this brings us back to our starting point. How does (classical) translation deal with transculturation? Can translation, as Martín Ruano puts it in the next subsection, live up to the expectations it creates as a metaphor?

In Semiotic alteration in translation. Othering, stereotyping and hybridation in contemporary translations from Arabic into Spanish and Catalan, the opening article of TRANSLATION STRATEGY, TRANSLATION POLICY, TRANSLATION THEORY, Ovidi Carbonell i Cortés tackles the central problem facing the translation of the type of texts discussed so far: how can a translator formulate a fundamentally different kind of knowledge and imagine a non-hierarchical relationship between same and other? Starting from the assumption that cultural translation always involves a metonymical move, in which key textual elements are used as symbols representing the foreign culture, the author explores the many faces of the widely used but unstable concept of foreignization. What is the foundation of presumed 'thresholds of acceptability' in translation and to what extent do translators challenge source culture expectations in their management of socio-cultural biases? The author explores the limits of strategies such as exoticism as well as the ethical issues involved in postcolonial translation, i.e. the need for a greater awareness of otherness (Bandia, López Heredia, Thompson,...), but the recurring problem remains the reproductive nature of translation which implies that any implementation of ethical attitudes must take into account the dialogic nature of the aesthetic-cultural reception context of translations. So what are possible/alternative strategies and what results do they yield? The author offers a survey of some of the major issues and currently used solutions and ends on a highly original suggestion of his own, based on the analysis of some of the pragmatic and semiotic processes at work in translations from Arabic into Spanish and 
Catalan. Reversing the original concept of foreignization the author shows that instances of further hybridization as well as ambiguous readings can actually occur in translation as a result of the familiarization of unexpected cultural referents.

Criticism of the concept of exoticism recurs in Goretti López Heredia's article El traductor visible de literatura poscolonial ante la tentación del exotismo. Starting from her experience as a translator of Mozambican Portuguese-African literature into Catalan, López Heredia takes up the issue of the translator's visibility-invisibility (Venuti). Some forms of visibility can constitute a valuable contribution to translation, but others, i.e. excessive instances of exoticism, undermine the intended effect. Using examples from her translation of the novel $A$ Varanda do Frangipani by Mia Couto, the author describes her modus operandi as the 'cultural translator' (Bhabha) of this typically postcolonial text. The translator should not simply enhance alterity and opt for a consistently foreignizing approach, but rather make his/her decisions, which may therefore go in different directions, based on a sound knowledge of the source language and culture. Foreignization is only warranted when the strategy is functional, that is, when it supports foreignizing strategies in the original.

Not only the concept of what constitutes postcolonial translation, but also who reads it, is investigated by Mary Snell-Hornby in Re-creating the hybrid text: postcolonial Indian writings and the European scene. An author may write for creative expression, but a translator will have a target in mind. Snell-Hornby compares what she calls a 'classic' translation of an Indian text aimed at an Indian audience into English (Sethu's Pandavapuram in English translation), with the hybridity displayed in a novel such as Arundhati Roy's God of Small Things, originally written in English and therefore aimed at an international audience, but one familiar with (post)colonial issues. She then proceeds to examine two German translations; one of this same novel, one of Salman Rushdie's Midnight's Children. Both translations are meant for a German public without inside colonial knowledge.

Still, whereas in Mitternachtskinder, the language has been neutralized into linguistically correct and stylistically unified formal German, in Der Gott der kleinen Dinge the translator has fairly successfully recreated the language 'norms' designed by the author, using a variety of strategies, and thereby creating a new target text. Like López Heredia, Snell-Hornby underlines how important it is for the translator to combine an in-depth understanding of the source text and culture - which also means an eye for norms and deviations from norms in the original, we would add - with considerable creative capacities. Where writing becomes translation, translation apparently becomes writing, or more visibly so. The problem that remains is: where does the threshold of acceptability (Carbonell y Cortés) in manipulating the source text lie?

The reader also has a role to play in Rosario Martín Ruano's Bringing the other back home: the translation of (un)familiar hybridity, which 
tackles a very particular problem of intercultural 'back-translation', one might say. Indeed, the author examines different translation solutions in the versions into (mostly) Spanish of multicultural works by various Chicano/a, Cuban-American, Dominican and Puerto Rican authors, originally written in (mostly) English but traversed by a Hispanic substratum. What happens when the other in the hybrid text coincides with the main language and culture of the potential readership of the translation? Like Snell-Hornby, Martín Ruano examines translations with a completely different approach (e.g. those by Enrique de Hériz and Liliana Valenzuela) pointing out that the divergences found in the behaviour of the translators is influenced by the expectations, read norms, prevailing in the context within which they work. Hériz's translations follow the line of the historically dominant centre and Spanish publishing houses, whereas Valenzuela's version produces a (new) subversive text that forces the readers to continue translating and to abandon their expectations of normative discourse. This state of affairs, the author also remarks, calls into question conventional translation studies terminology for describing attitudes and behaviour towards the other: the usual categories are inadequate because of their binary perspectives. In fact, these categories are relative (see also Carbonell y Cortés) and translation studies needs to enlarge its vision, including its distinctions between original and receiving culture (Bandia) in order to explain the workings of translation when it comes to linguistically ambivalent and pluralized texts. New types of texts require new types of translations, new types of readers and possibly also new types of translation theories.

The underlying role of the world market and publishing houses in determining translation norms, touched upon in Martín Ruano, is elaborated in Laura Calabrese Steimberg's Lengua y mercado en el mundo hispanohablante: un acercamiento al estado de la traducción literaria. The focus is on literary translation in Spanish Latin America, with examples from Argentina. Due to the global policies of publishing companies in Spain, the former colonial motherland is well on its way to colonizing its previous colonies all over again, turning Spanish Latin America into a passive outlet for translations produced in Spain. In the past, countries such as Argentina used to occupy an intermediate position (a peripheral one with regard to Spain, a central one with regard to other Spanish Latin-American countries), and as such they played a pioneering role in the introduction of foreign literary models. In fact, in the heyday of Spanish literature from Latin America (the 1970s and 1980s), Argentina seemed set to usurp Spain from its culturally dominant throne or at least become a 'privileged partner'. That trend appears to have been reversed. A corollary of this is that the different current variants of the Spanish language are not proportionally represented in the field of literary translation. This has led to the rise of some local initiatives demanding a place for their own particular language variant by promoting different translations of classics from world literature, such as Shakespeare, in a reaction against the imposition of the standard language from Spain. 
In a more extreme situation, non-translation may appear to be the best survival plan when faced with the oppressive domination from the culturallinguistic centre. In Translation and postcoloniality in Ireland: the particular and peculiar relationship between Irish Gaelic and English, Tok Thompson posits that in order to asses the impact of translation on a minority culture the role of the translator and of translation, as well as the original text must be considered within their larger socio-political context. In Ireland the particular situation of the threatened Gaelic language highlights translation's ambivalent nature as saviour and destroyer: the translation of Gaelic texts helps preserve Gaelic culture and even promotes it. In the previous section, Tymoczko points out that the $20^{\text {th }}$ century boom in Irish literature owed much to preceding translation policies. However, if all Gaelic texts are translated, what then happens to the incentive to study the language? What happens to the threatened linguistic community, and the 'fount' for translations itself? In Ireland, Thompson writes, being a 'good translator' may therefore involve a concern with the preservation of the linguistic community one translates from, and, possibly, the decision not to translate; translation becomes problematic when the language itself is to some extent the raison d'être of a piece of writing - even if this translation is the onset of further creative activity, including the creation of new hybrid forms. Still, the author offers this view as but one solution to the problem and indeed stresses the need for awareness of translation's hidden powers. He also considers other options that might minimize 'translational damage', and cultural re-education stands out once again, as well as the need for translators to engage in the culture they translate as participant-observers. The limits of translation's creativity may have to be compensated by more active contributions from readers to whom translations are no longer invisible.

We remain focused on the limitations of translation - can it live up to the expectations it creates as a metaphor - in the next four articles of the collection, but also on the way in which transcultural source texts open up the very concept of what translation is, forcing it to expand and testing the abilities of the reader. This happens in the translations that turn into creative writing, studied in Simona Bertacco's The Canadian feminists' translation project: between feminism and postcolonialism, dealing with the contributions to translation studies by Sherry Simon and Barbara Godard. The political agenda of translation and the issues of identity and cultural allegiance that it raises (Lefevere, Venuti) are also a central concern of feminist theory and the challenge it offers to Canada's deeply rooted internal linguistic-cultural barriers. The notion of the 'violence' of translation also returns in this article, be it from a more positive perspective in the shape of the representation of (feminist) difference. The feminist stance against patriarchy and its language, is reflected in the way feminist translation theory turns the translator into an active participant in the creation of alternative meanings. Just like the texts of the feminist writer Nicole Brossard are characterized by their 'womanhandling' of language, so Godard's translations of them are rewritings (Lefevere) which force the reader to focus on language and its 
conventions. However, does this practice not become problematic when applied to other types of texts, especially feminist texts by postcolonial writers working outside the western feminist framework (Spivak)? It is an issue that merits consideration, but translation is always a form of disrupture, and rather than censor translations it may be more useful to urge readers to look at translated postcolonial texts as a battleground (see Thompson). Seen from this perspective, the Canadian feminists' project and the way it transgresses established borders between Canadian communities is an example of minoritizing translation, the only form of rewriting capable of promoting cultural renewal and difference (Venuti).

A different type of borderline is investigated in Translation and/as simulation: first attempts at imitating James Joyce's Ulysses in Hong Kong, 1960-1963 by Leo Chan. Highlighting the constructive input translation studies has to offer comparative literature, Chan investigates different approaches to the study of literary immitation and its relations to translation in the West and in China. His study looks at three Chinese Joyce immitations. First, Ye Weilan's "Youlisaisi zai Taibei" or "Ulysses in Taibei", which simulates Joyce's stream-of-consciousness method, but strongly departs from the original in various ways, next Lu Yin's "Peiqiang de Jidu" or "Armed Christ", which is more closely imitative and exploits several features of style and subject matter of Ulysses, and finally Liu Yuchang's Jiutu - The Drunkard, which makes the most marked use of Joycean narrative strategies. The first translation to be published in China, Ye Gongchao's rendering of part of the "Hades" episode, closes the ranks. Chan explains the popularity of these imitations in China, in spite of imitation's subservient status, exploring the way in which it may have paved the way for translation. He also reckons with the culturally determined points of contacts and divergence between these forms of text production, which may be more closely related to each other in the West than in China. His article is a welcome contribution to the wider debate surrounding translation theory and practice today as it tries to shake off its predominantly Eurocentric or western perspective.

The following contribution, Danielle Cyr and Alexandre Sévigny's Traduire pour transmettre: le cas des textes amérindiens also offers us a glimpse into the problems involved in translating cultures from across a wider cultural divide, and is written from a different perspective, i.e. a linguistic one. The problems under consideration are those one faces when attempting to translate texts written in certain north American Indian languages from the Algonquin group into English or French. Taking a view that is quite different from Thompson's, the authors stress the need for translation as a way to preserve these languages threatened with extinction. The problems are formidable due to fundamental differences in the world views underlying Amerindian languages and the different ways in which their grammars work: some of the grammatical categories we take for granted simply do not exist in Algonquin. A form of intranslatability that can only be compensated to a limited degree is the result, and is further compounded by 
western influences exerted on the source languages under colonization. Indeed, the whole picture is a highly complex one and yet translations are made, both into and from Algonquin, even if these were, until very recently marked by paternalistic attitudes - another example of the 'violence' of translation. Still, the authors present their Electronic Encyclopedic Dictionary of Contemporary Migmaq in which the English headwords have been ordered with a view to accomodating Mìgmaq categories, and point out that a revival of Mìgmaq literature is underway. It is trying to locate a 'middle ground' by publishing bilingual editions or English texts with their very own variants of foreignizing effects.

The assertion of cultural identity is but the other side of the coin of globalization, as we mentioned at the beginning of this introduction, but it is the identity-effacing effect of globalization that is the topic of Publicidad $\mathbf{y}$ traducción: el robo de mitos y contramitos en un mundo globalizado, the article by our last contributor María Calzada Pérez. The author uses concepts from translation studies (Bassnett) to expose the ideological rewriting of the messages of advertising. In order to avoid problems, the globalized economy attempts to produce 'translatable' messages that skirt the need to take language or culture-specific issues into account, and power relations being what they are, it is the North American world view that determines their shape. Using Barthes's concepts of denotation, connotation, myth and contramyth, Calzada Pérez analyses three ads and their translated counterparts. She combines Barthes's ideological critique with the analytical translation model designed by Vidal Claramonte, consisting of three phases. Calzada Pérez focuses on stage two, analysing the genealogy of power as it appears from the three ads joined to the article and looking into the roles and responsibilities of the designer-writer as intercultural go-between, showing that even in advertising some limited resistance to the blurring of difference remains possible.

Do we thereby end with a rather negative view on the restricted possiblilities translation has on offer to counter globalizing trends? Actually, we would rather not end at all. Not ending would appear to be the most appropriate rendering of the discussion at this point: as translation and creation mingle more explicitly than ever, the myriad of text production that ensues seems virtually limitless and opens exciting prospects for research. Some articles in this collection stress the role of translator-training institutes in increasing awareness among translators of their own ideological stance and the ways in which it will inevitably influence the translations they produce. Various articles also point to the importance of the reader's contribution in the shaping of meaning. Linguistica Antverpiensia persists in its tradition of giving a voice to authors in many languages. For this introduction their voices have been translated by us into the idiom of the centre - although we hope that the 'violence' of our translation has remained within limits. We now invite you to burst our text's borders and let the book speak to you in its many tongues, hoping that our orchestration and your orchestrations of its sounds will turn it into a symphony. 


\section{Bibliography}

Bassnett, Susan (1998). "The Translation Turn in Cultural Studies.” S. Bassnett \& A. Lefevere (eds) (1998). Constructing Cultures. Clevedon: Multilingual Matters, 123-140.

Bassnett, Susan \& André Lefevere (eds) (1998). Constructing Cultures. Clevedon: Multilingual Matters.

Gambier, Yves (2003). "Introduction: Screen Transadaptation. Perception and Reception.” Y. Gambier (ed.) (2003). Screen Translation. Special Issue. The Translator 9 (2), 171-189.

Gentzler, Edwin (2001). Contemporary Translation Theories. Rev. $2^{\text {nd }}$ edition. Clevedon: Multilingual Matters.

Hermans, Theo (1999). Translations in Systems. Descriptive and Systemic Approaches Explained. Manchester: St Jerome.

Tymoczko, Maria (1999). Translation in a Postcolonial Context. Early Irish Literature in English Translation. Manchester: St Jerome.

Van Vaerenbergh, Leona (2002). "Linguistics and Translation Studies. Translation Studies and Linguistics. Eine Einführung." L. Van Vaerenbergh (ed.) (2002). Linguistica Antverpiensia New Series 1, 13-26. 